\section{Quality in Electron Microscopy}

Tony Bruton (1), Steve Chapman (2) and Paul Harding (3)

1. E.M. Unit, University of Natal, Pietermaritzburg, South Africa. 2. Protrain Courses, Buckingham, England. 3. Integrated Systems Mgmnt., Nissan Motor Co., Rosslyn, South Africa Steve Chapman [protrain@emcourses.com]

\section{Introduction}

Does quality exist in the electron microscope laboratory? What is quality? Quality is when a product or service meets all of the customers' requirements, is delivered in the correct quantity at the required time, to the right place and at a price the customer is prepared to pay.

In an open competitive environment all of the above would apply. In an electron microscope laboratory are we totally satisfied that we have given consideration to our product? We also provide a service, are we happy that the service we provide is of a sufficiently high standard, a standard that we would expect if we were the customers in a hotel or a garage? If we follow the example of world trends in industry, then simple product and service quality, in isolation, is no longer sufficient, and focus must be given to a total quality approach. For a long time, quality was associated with the task of inspection, or other activities connected with a traditional quality control function. Recently, we have seen the expansion of quality standards covering many manufacturing and service industries. Government departments, hospitals, and top manufacturing companies have insisted on suppliers of goods and services being certified to a quality system standard. This need for standardization led to the acceptance of the International Organization for Standardization (ISO) 9000 series of quality standards, as the normative reference, by over eighty countries world wide. There have been many debates about the effectiveness of applying such a documented standard, which many saw as merely a consistent, but not necessarily an improved, way of working. However, there is no escaping the need for overall quality improvement, both in product and service, in order to survive in the current scientific climate.

Before a standard for quality may be applied, it is important to have a very clear definition of what the elements of quality mean: $i$. Quality Control (QC) is the systematic assessment of product or services to a known standard, in order to check their conformance. It does not improve quality, only highlights its absence. Similarly, it does not always identify the cause of non-conformance. The only consistent way to achieve a desired quality level is to eliminate all the root causes of non-conformance at their source. ii. Quality Assurance (QA) activities are a little more involved than just pure inspection. These tasks cover the setting and verification of standards to ensure the integrity of the results; do they comply with pre-determined requirements? The QA function audits the departmental activities to ensure an appropriate uniformity and conformity, but this activity can only be truly effective if those activities have been formally documented. This function directs the control process through continually auditing and reporting on the process and orchestrating improvements. The QA function should contribute to ensuring that both department and customer requirements are satisfied. Unless a broad view of quality improvement is taken, many of the benefits of introducing a formal documented system are ignored. This has mainly been brought about by the misconception that documenting a system is bureaucratic and stifles creativity. This is not the case if the standards are fully applied and used as an improvement tool. A documented system is also an excellent means of improving internal communication, particularly when interfaces between departments are established through procedures. This applies not just within individual departments but across functions within a department. Therefore "quality" starts by assessing a process, setting down "exact procedures" for that process, auditing the actual actions and comparing them with the "exact procedure." Finally, looking at the product of that process and procedure to determine the worth of that product, and then asking "Could it be improved and if so how?" If an improvement is perceived this can be included within a new modified "exact procedure" and the auditing process is repeated. The Japanese use the word Kaizen (Ki-zan) to describe the ideal quality improvement cycle, this means gradual unending improvement, doing little things better, setting and achieving ever higher analysis, this is produced after the specimen has been prepared and examined within the microscope. A micrograph in turn may have been processed through a dark room where the procedures for developing and printing took place. Each action should be part of an "exact procedure," a procedure critical to the standard of the result. Unfortunately, the "quality" of results from an electron microscopy laboratory, micrographs or analytical data, are seldom assessed internally, and rarely have quality assurance personnel set specific quality standards. This paper outlines procedures that would bring "quality" into the laboratory and improve the standards in that laboratory.

\section{A Quality Procedure}

For any quality improvement program to be successful there must be an awareness created on the importance of quality throughout the entire department. Once the awareness has been created, a comprehensive program of quality education and training may be implemented. All quality gains must be consolidated before moving to the next improvement phase. Planning is essential for the development of a quality management system, which addresses problems and is capable of establishing corrective actions that can be implemented through the audit improvement cycle.

Many departments currently operating to a quality standard, such as ISO 9002, start the development of a documented quality system with very few formal procedures already in place. There are sure to be informal practices that have been entrenched over a period of many years. The challenge at the start of a quality improvement program is to mould a formal quality system around your existing informal procedures. The development of good practices at this stage will assist in the move to a Total Quality Management culture later on. A quality policy, which ideally should be aimed at satisfying the customer, must be reflected through the entire documented management system. The development of the program may then be compared with the actual working practices and against the department's stated policy, goals and objectives, something often lacking in non-competitive environments. Each section within the department should develop their own formal procedures and working instructions but in conjunction with the overall quality system coordinator(s). It is important to remember that procedures should remain constant and not be affected by instrument changes. At this stage of the quality system development there is often an enthusiasm within each individual unit of the department, to complete procedures and work instructions. Care must be taken to ensure that each activity that is being documented not only supports stated policies, but also "talks" to other related procedures being developed in other areas. A good documented system will reflect the natural flow of department's activities. Internal audits should now identify relationships between individuals, the areas of preparation, the instrumentation, the dark rooms and any other facet within the department. It is important when first starting the audit function to remember that audits are tools for improvement and not "witch hunts." It is well worth the effort at an early stage to ensure adequate auditor training takes place. Through ongoing communication between sections, greater knowledge and therefore understanding of broader issues will help strengthen the business of the department.

Taking the example of the integrated system diagram, reference the figure, if each discipline identified worked independently, we would have sixteen teams working towards producing a quality improvement program. Looking at the number of triangles that appear in the diagram it is far more than the basic sixteen, twenty-seven in fact! Such is the complexity of developing a fully integrated quality system. Quality improvement must start with feedback from your "customer." If the internal as well as the external customer are considered, then the needs may be more easily satisfied. At this stage, a document management system will be in place, but in order for it to be effective it now has to be audited.

\section{Auditing the System}

Regular audits must take place in order to improve your management system. The frequency and scope of the internal audits will depend on the maturity of the system. To gain real benefit from the audits, results should be fed back to senior management and corrective actions must be followed through. A Plan, Do, Check, Action (PDCA) should be introduced to close out any nonconformity's. Because of the reliance upon the microscope or analyzer performance, constant assessment of the instruments and their operators are essential in the development of a well-executed quality system

\section{A Quality Procedure for Electron Microscopy}

Set out below is an example of how to develop a typical E.M. quality procedure and audit:-

1. Set down "exact procedures" for specimen preparation and the operation of the microscopes and accessories. Refer to books relating to the preparation of specimens and the operation of scanning and transmission electron microscopes. Do not accept a regime that, for example, limits the accelerating voltage, specimen position and spot sizes to be used in an instrument. There are too many publications that seem to suggest, wrongly, the scanning electron microscope will only operate at $25 \mathrm{kV}$ and 
that the ideal accelerating voltage for transmission electron microscopy in biology is $80 \mathrm{kV}$. An advanced manual should be produced encompassing all the variables and their relationship to the specimen, the information required and the final micrograph or analysis.

2. Appoint a team to oversee all areas of quality and to inspect all micro-

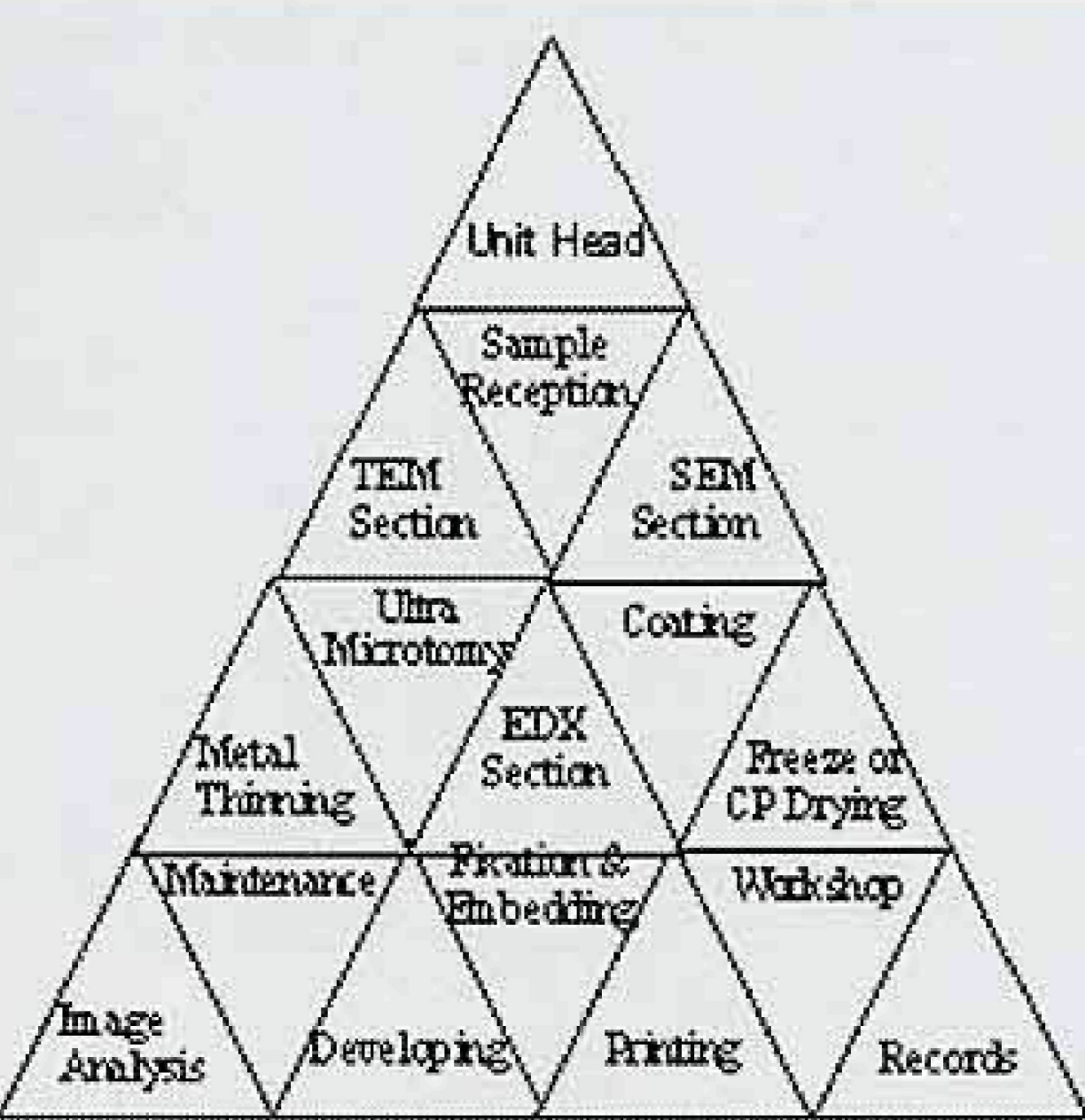

graphs and $\mathrm{x}$-ray analysis results leaving the laboratory.

3. An audit check list should be drawn up to cover all the functions that are part of the quality management system. This list may be a straightforward yes or no questionnaire, or it could contain questions with importance weighting and a sliding scale of points depending on implementation.

4. It is important to understand the significance and inter-relationships of the three elements, internal audit, preventative and corrective action, and management review. This is the basis of the quality improvement cycle that is necessary in any department to effect quality improvement The first phase ISO audit is for consistency. The second phase is to correct any non-conformity and if necessary, apply preventative actions to eliminate further deviations from the planned actions. The third phase is the management review when the question must be asked, "are your systems documented, implemented and maintained, and are they effective?" Do not expect too much from your first audit. If the system is being developed from a low base of formal procedures there will be a lot to audit. The system will slowly take shape, as more procedures are prepared. Beware of trying to import someone else's system. What works for them will not necessarily work for you.

5. Audit the performance of the instruments in the laboratory as well as that of the instrument operators.

6. Ensure that each operator takes a performance test micrograph e.g. every two months.

7. Ensure each microscopist and associated photographer present their best efforts for discussion, e.g. once each month for staff to make comments on their quality and suggestions for improvement.

8. From the monthly audit meeting rectify any areas of the laboratory process that are seen to be inadequate. Good communication should be part of quality, once in place throughout your department make it part of your audit schedule. If something works well for you, document it, and then audit it.

9. Routinely audit the calibration of the microscopes within the laboratory.

10. Routinely audit the contamination and drift rates of the instruments and the pump down time of each section of the instruments.

11. Routinely audit the calibration and resolution of the EDS spectrometers as well as the quantitative analysis accuracy against a known standard, check the litres per hour of liquid nitrogen use.

12. Ensure that external service staff takes performance test pictures or standard analysis prior to leaving the laboratory after a service visit.

13. Every spare part for each instrument should carry a label listing the source, the contact telephone number, delivery time, cost and if possible, an alternative supplier.

14. Collate data that would ensure that the laboratory could run efficiently no matter which members of staff were absent, this is essential to a well run unit.

1 and 2 will require help from industry experts in order to ensure that procedures are outlined that fully cover the variables involved in an operation. Documentation that does not incorporate variables, and reasons for choice, could not be said to enhance a laboratory's status. Too many laboratories without resulting to an outside consultant regard their work as superior to others; our evidence is that many are totally incorrect.

\section{Initial Instrument Evaluation}

Microscopes within an electron microscope laboratory are built to be within specific tolerances in relation to resolution and magnification. The final specification from the manufacturer should include details of magnification accuracy, drift rate, contamination rate, and resolution. On delivery, the onus is on the installation engineer to confirm that the microscope meets its specification. To accept a microscope that does not fall within such a specification is the responsibility of those who manage the electron microscopes in the laboratory. Energy dispersive analytical facilities are also specified to attain a specific resolution; this too should be confirmed on completion of the installation of this accessory.

Weakness is often displayed by those responsible in this area by accepting an instrument that does not conform to specification, or by not insisting that the manufacturer's representative audits the installation. Without this start point for a new instrument, inferior quality is being accepted!

\section{Instrument and Staff Evaluation}

Microscopes and their accessories may well meet specification when new but what performance may one expect today and how accurate is the magnification calibration? Similarly, you may have high resolution microscopes but what are the performance capabilities of your staff? The first audit requires an evaluation of the instruments and the staff who operate them, followed by periodic reassessment of their capabilities. Procedures are outlined here for the transmission electron microscope and for the scanning electron microscope; where to the best of our knowledge detailed test procedures have not been published. X-ray analytical facilities may also be evaluated using the documented methods for the determination of resolution.

In many laboratories, staff may rightly claim that they do not need to push the instruments to their limit during their normal day to day workload. The incentive to take resolution pictures on a regular basis is that when pushing the instrument to its limit, problems will be displayed long before they affect the normal work of the laboratory. In this way, the problems may be discovered and corrected, with the minimum of disruption to the laboratory. There is no doubt that encouraging an operator to push themselves and the instruments to their limits also develops the general operating techniques of the operator.

\section{Specimen Selection}

It is most important that any test specimens used to audit an instrument are from a traceable source and are certified by a recognized body. In this guide to improving a laboratory performance we are suggesting that staff and instruments are assessed using non traceable standards, but only as a starting point to determining the performance of instruments and staff.

\section{Scanning Electron Microscopes}

Traditional methods for the evaluation of resolution in the scanning electron microscope rely upon the imaging of a high-density particle on a low-density substrate. The most popular method is evaporated gold on a carbon substrate. Although most manufacturers use this method, it is subject to abuse, there is no inbuilt magnification standard and therefore, the evaluation of the image may only be made through measurement. To simply judge the specimen by appearance as most scientists do, could lead to a misleading result.

An ideal specimen for the evaluation of scanning electron microscope performance is dried polystyrene latexspheres, sputter coated with gold, or for the evaluation of higher performance (e.g. field emission instruments) gold palladium. The specimen requires very pure polystyrene latex that is allowed to settle and dry down over a period of time sufficient for it to form a solid block. The block is fixed to a specimen stub with silver DAG and the adhesive allowed to dry. The dry block of latex is pricked with a pin to open up the internal structure. The specimen is then sputter coated a number of times, for one minute at 1,000 volts and $20 \mathrm{~mA}$, with a specimen target distance of $5 \mathrm{~cm}$. At least one minute is allowed between coatings and the procedure repeated for a total of 5 to 9 coatings

This procedure produces a specimen that contains hexagonally packed latex spheres with gold structures and cracks on their surface. If the spheres are aligned to place the fracture in a flat plane, the image of the hexagonal packed areas anywhere on the specimen may be compared. In the opinion of the authors there is no need to measure the structures on the specimen, as a careful visual evaluation will display an improvement or degradation of the instrument's resolution and the capabilities of the operator. The specimen, unlike gold on carbon or gold on magnetic tape, has an inbuilt dimensional standard in that the latex particles are of a specific size $(\sim 0.25 \mu \mathrm{m}$ are ideal). This feature in its self, simplifies the evaluation of test micrographs and is unique among scanning electron microscope test specimens. There is no doubt in the size of the structures because the spheres act as the magnification standard. For those who are unable to make the test specimens successfully, they are available from the Cantock's Enterprises, Dept of 
Chemistry, The University of Bristol, Cantock's Close, Bristol, England. OR make contact with your local Physical Chemistry Department.

Transmission Electron Microscopes

In order to determine the performance of an operator there is no point using a crystal lattice test as used by the manufacturers to present their resolution capabilities. A lattice only tells you if you have reached a certain resolution level, it does not tell you how far short you have fallen, or even if you are able to attain a higher resolution. The Fresnel fringe around a hole however provides you with a resolution figure from $5 \mathrm{~nm}$ down to $0.45 \mathrm{~nm}$ (Haine), and it is therefore this specimen that is ideal for a resolution test under the circumstances of this paper. In order to measure performance, the instrument will also require a magnification calibration at the same level. The test should be made in excess of $100,000 \times$ and that will require a crysatile or similar crystal lattice specimen for calibration (Menter). The test specimens mentioned here are available from any electron microscope accessory organization.

\section{Energy Dispersive X-Ray Analytical Systems}

A simple aluminum/copper or aluminum/cobalt standard, which is available from most accessory organizations, is sufficient for resolution testing. The aluminum offers a low electron volt calibration and resolution point with either copper or cobalt being used for middle range performance.

\section{Performance Monitoring Procedures}

It is not a criticism of electron microscopists if they are unable to take high resolution micrographs; while many people are able to drive cars, few are able to race them successfully without practice! Therefore, we may assume that if a microscopist is forced to take performance test pictures on a regular basis, their operating technique will improve. Fitting a form of instant micrograph feature to the microscopes may make a further step in the direction of improving the quality of micrographs produced in a laboratory. In this way, the microscopist will be able to assess each micrograph and make corrections to their procedure if necessary. The instant feature may also be backed by the conventional photographic emulsion, once the ideal conditions for the micrograph have been achieved. In the case of scanning electron microscopes this requires the use of Polaroid or electronic image-reproduction procedures. In the transmission microscope the addition of modern imaging facilities will also offer the use of electronic image production procedures.

\section{Determining Performance in Scanning Electron Microscopes}

\section{Resolution Test}

Before testing the machine, the instrument should be clean and set up in such a condition that the full potential of the instrument may be realized. In an instrument using a tungsten hairpin filament the gun geometry required would not be that one would use for extended filament life. It requires the filament to be placed in such a position within the cathode that the emission current will be:-

1) For a Japanese instrument around 90 to 110 micro amps above the standing current for that kilovoltage, while the bias or emission current setting is at its half-way position.

2) For a Camscan, around 120 to 150 micro amps (may be indicated as 1.2 to 1.5 ) above the standing current for that kilovoltage, while the bias or emission current setting is at its half-way position.

3) For a Philips/FEl around 80 to 100 micro amps while the emission current setting is at its half-way position.

4) Field emission instruments require an emission current of at least 10 micro amps.

Place the specimen in the microscope and select the accelerating voltage that is the subject of the test. Switch on the accelerating voltage and leave the instrument in this condition for one hour to allow the high voltage tank to stabilize. Not until the heat gained by the components within the tank equals the heat lost through its walls will the high voltage reach maximum stability and offer maximum performance. Investigate the specimen at the working distance selected for the test, less than $5 \mathrm{~mm}$ being ideal for a modern conical final lens. Look for areas on the specimen that display hexagonal packing in the perfectly flat form as they are ideal for a resolution comparison. The magnification of the test micrograph should be at a level to test both instrument and the operator. On an instrument with a tungsten hairpin filament, originally guaranteed for around $10 \mathrm{~nm}$ resolution a magnification of $50,000 \mathrm{X}$ is appropriate at $10 \mathrm{kV}$ or more, whereas $25,000 \mathrm{X}$ is more suited to accelerating voltages of less than $10 \mathrm{kV}$. For instruments able to attain better than $5 \mathrm{~nm}$ resolution it is more appropriate to double these figures and for field emission instruments only magnifications of four times these levels would offer a good test.

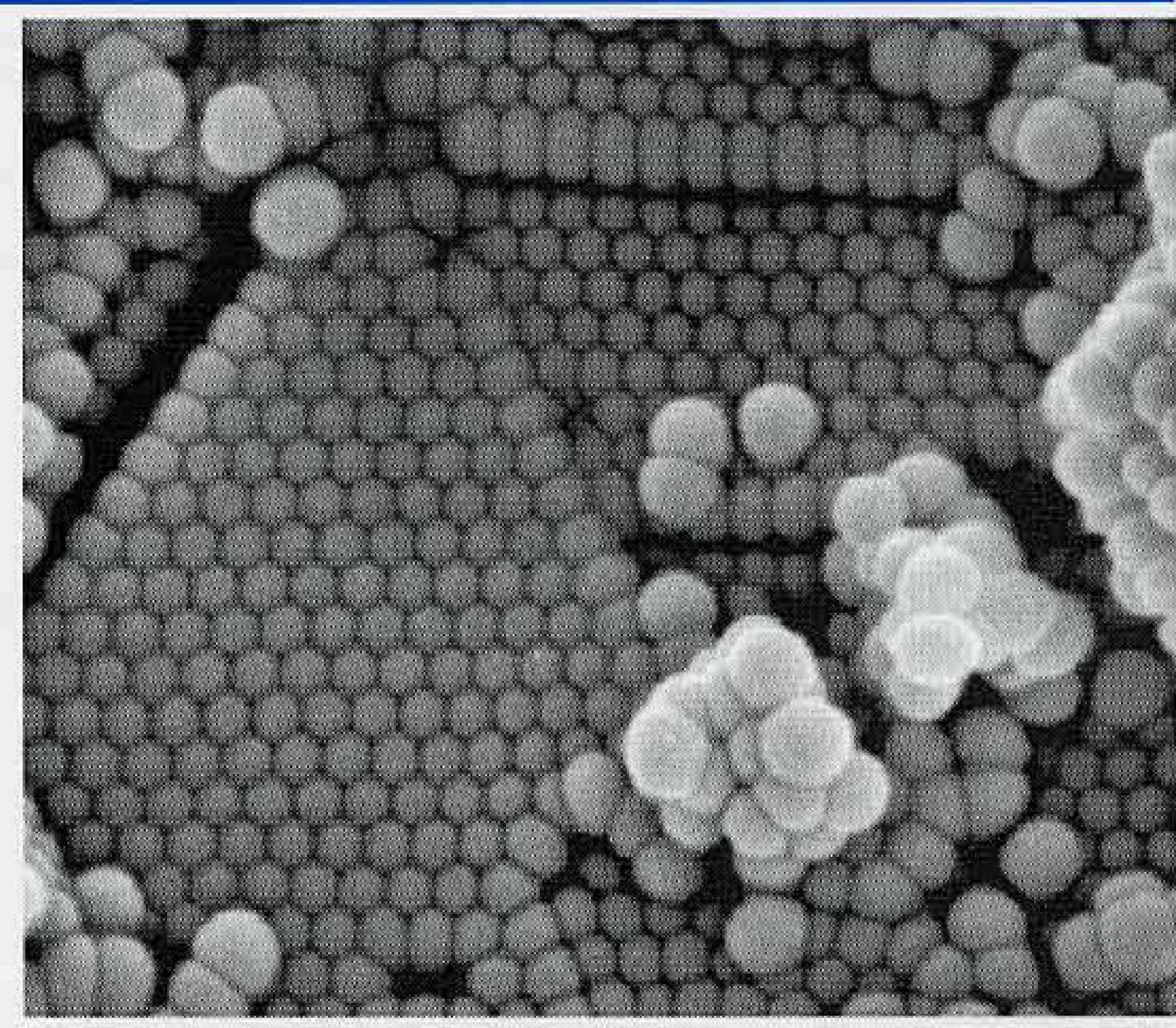

Take pictures of a fresh area within one screen width of that which you used to focus and correct the astigmatism. Move between these positions with the electrical deflection often known as "image shift", as a stage movement will unsettle the specimen and possibly change the focus. Do not dwell on the area of interest as this will contaminate the specimen and soften the image. Instruments vary the size of the probe through the use of their condenser lenses, the appropriate control may be called spot size, condenser lens (c-lens), resolution or probe current; in this manuscript the term spot size will be used. You should expect to use a spot size near to the limit of the system when attempting to attain the highest resolution for a particular microscope. It is not possible to determine the ultimate resolution of the instrument other than by taking a series of pictures over a range of spot sizes, the changes are usually too subtle to observe on a conventional CRT. One would expect the image on the viewing CRT to be very noisy under the conditions required for maximum resolution, focus and astigmatism correction being made only by looking for maximum contrast. Under these conditions it is very unlikely that a clear image will be displayed, noise will dominate.

\section{$\frac{\text { Measurement }}{\text { Calibrated Magnification }}=$ Resolution}

\section{Magnification Calibration}

Low magnification calibration standards are available in the form of a metal grating or the more abundant transmission electron microscope specimen support grids. The latter are usually well documented in accessory catalogues and offer very low cost, and are very accurate test specimens. There are two styles of standard that are applicable to the scanning electron microscope at medium to high magnifications, either a metal grating or a carbon replica of a grating, for a transmission microscope test specimen, the difference is cost.

The test specimen should be placed in the microscope taking great care to ensure that it is sitting flat on the stage. Preliminary investigations in this area using a bubble spirit level are advised if you are not confident that the stage is truly flat when indicating 0 degrees. Switch off any accessories that interfere with the conventional scanning process and may lead to irregularities in magnification, for example scan rotation, dynamic focus and tilt correction. It is important that you fully understand your imaging media. Older scanning electron microscopes offer a 1 to 1 image recording on 4" $X 5^{\prime \prime}$ Polaroid film but with any other media, a change in this ratio is almost certain to take place. Full details of any ratio changes should be available in the microscope's instruction manual or from the supplier. Accelerating voltage, working distance and spot size all play a role in the level of magnification being attained. Be aware that a spot size change will almost always give a magnification change on older instruments, unless the manufacturer attempts to compensate changes of this type. A simple test of this feature is to focus at one spot size and, after switching to the next position, recheck the focus. Any change in focus indicates a need to make a focus correction that in turn will change the imaging magnification (due to a change in focal length). 


\section{IXRF Expands "Coast to Coast" celebrating their 10 year anniversary}

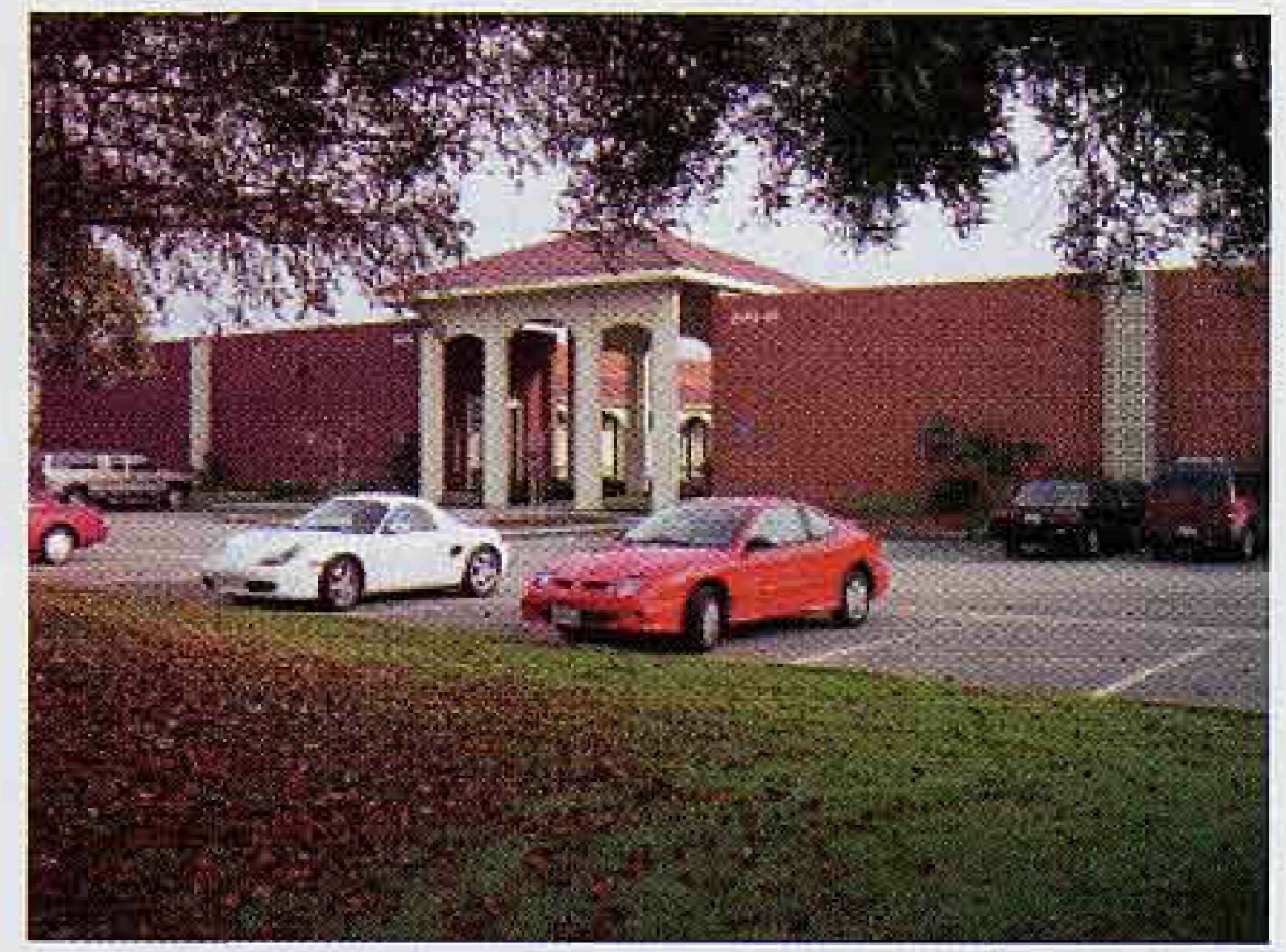

IXRF's Silicon Valley development facility

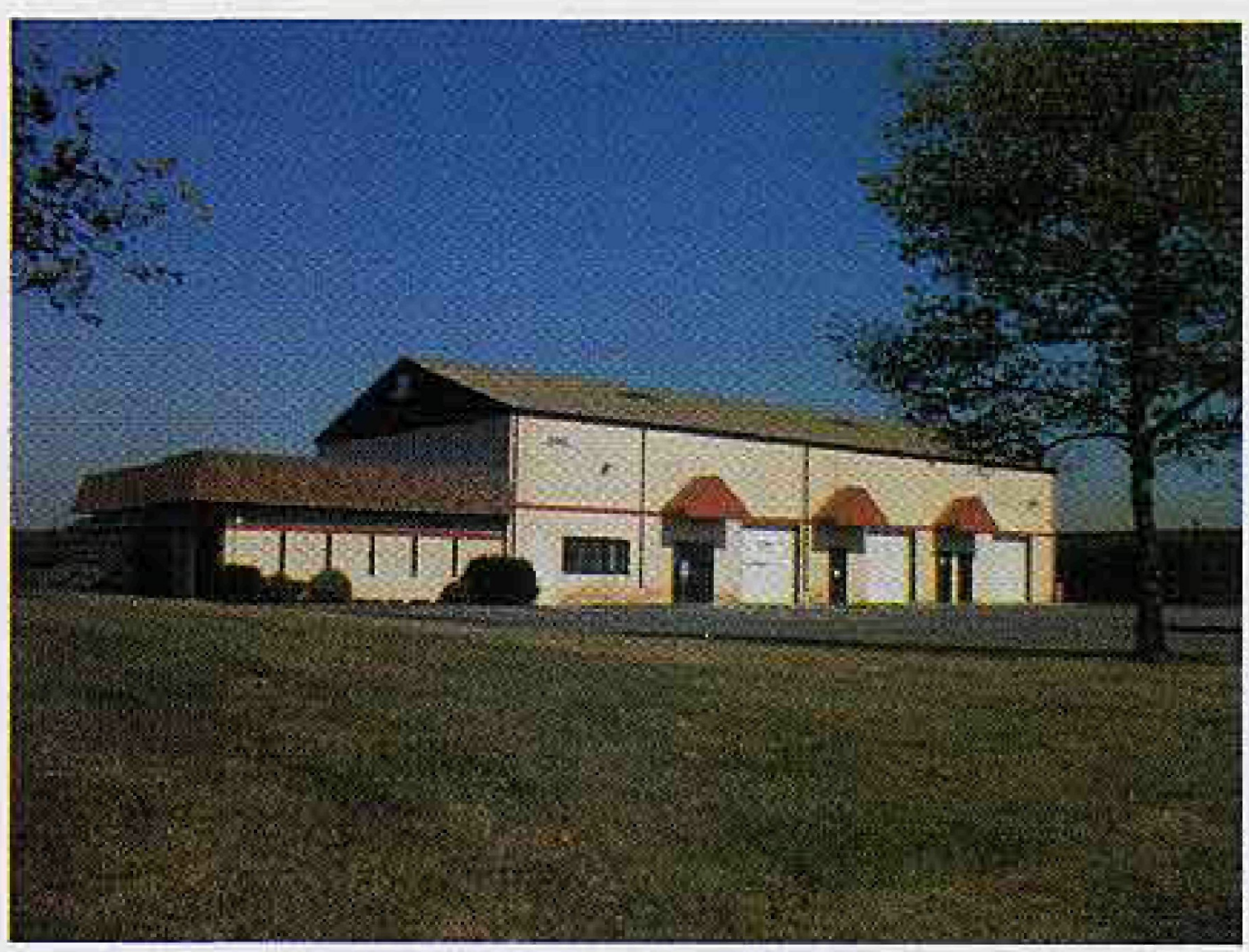

IXRF's Trenton New Jersey facility

IXRF thanks its loyal customers for their support in the growth of IXRF. At IXRF, we believe "satisfied" customers is the best way to sell more systems. By offering free software upgrades, customers never have to purchase another system. Even IXRF's first customers, 10 years ago, can still download the latest software and have all the latest features. Through customer suggestions, IXRF's software has become the leading Microanalysis software rivaling the major EDS companies -at a fraction of the cost. To our customers, thanks again!

Major Milestones

1992: IXRF personnel begin planning future products.

1993: Los Alamos National Lab receives the first IXRF system.

1995: Digital Imaging, Feature analysis, and X-Ray mapping are added into the systems.

1997: IXRF completes the first 100\% Integrated EDS Microanalysis system in history (developed for LEO Electron Microscopy).

1998: Jetscan Engine Health Monitor wins a millenium award from the British government (developed for LEO Electron Microscopy).

1999: IXRF Completes the "Particle Scan" offering the first truly integrated Particle Analysis inside the operating system of the SEM (developed for LEO Electron Microscopy).

1999: IXRF designs a new hardware interface allowing the use of Oxford PentaFET detectors for upgrading existing customers.

2000: IXRF completes the second fully Integrated EDS system, this time for JEOL Ltd.

2001: IXRF completes Particle Analysis on the Integrated JEOL Ltd product line.

2002: IXRF mounts the first micro $x$-ray tube on an SEM, to offer the first fully-integrated XRF and EDS microanalysis within the SEM.

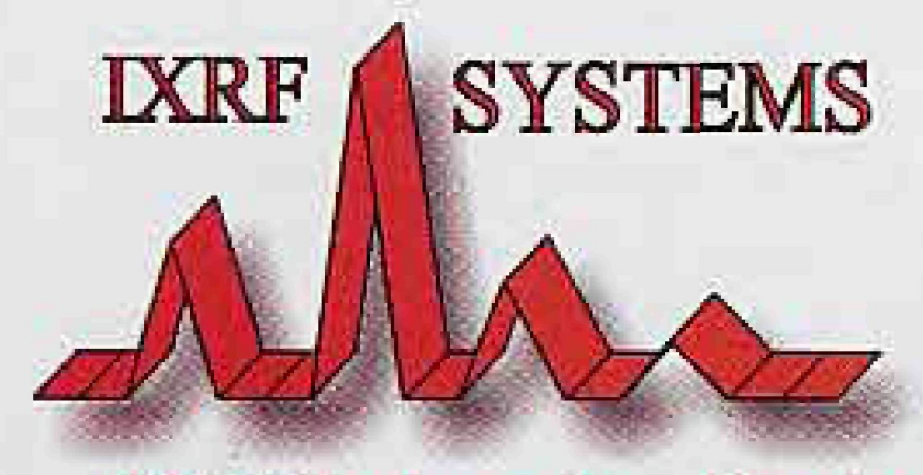

IXRF Systems, Inc., Houston, TX, USA, www. ixrfsystems.com $\mathrm{Ph}:(281) 286-6485 \mathrm{Fax}:(281) 286-2660$

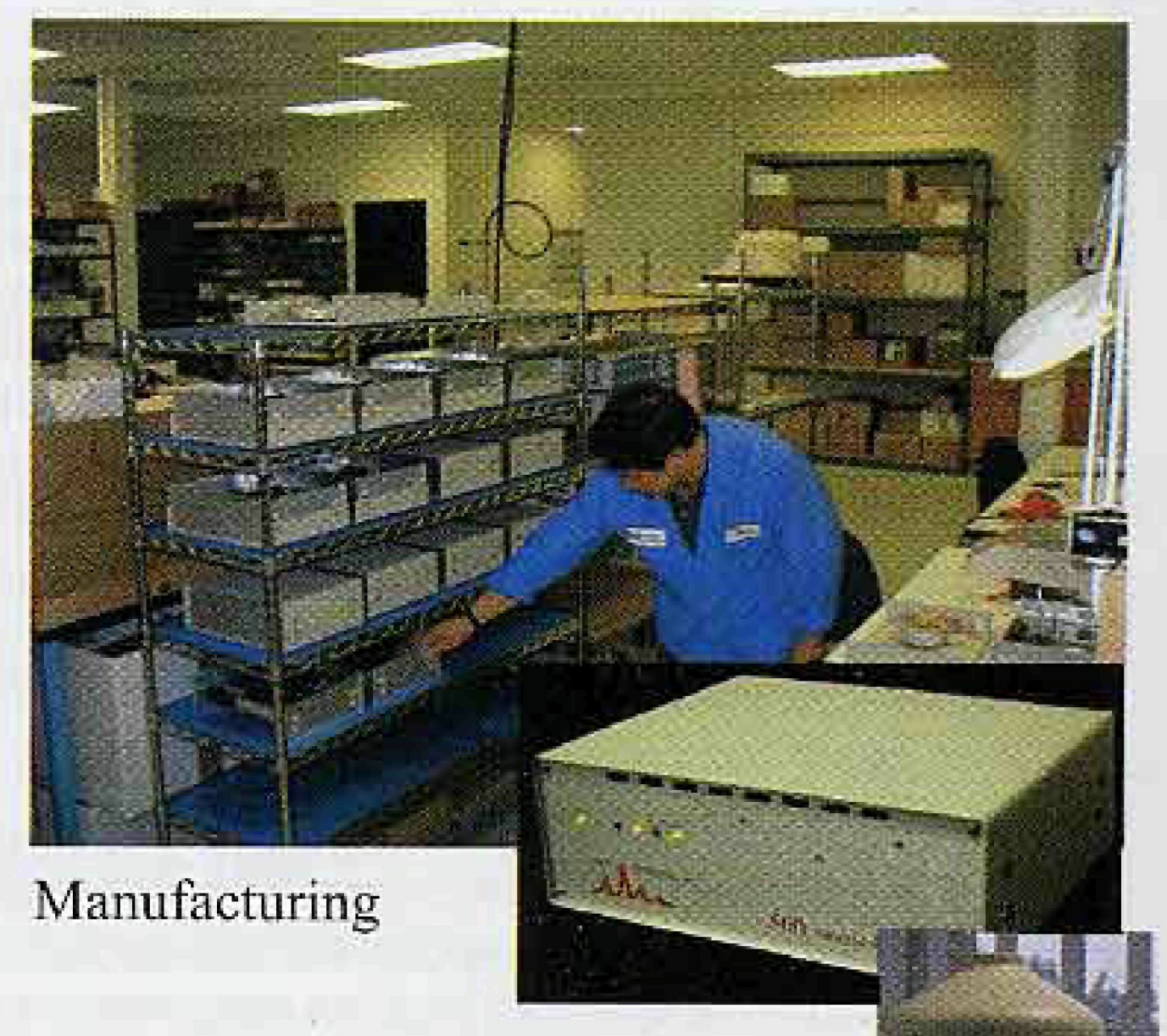

New Detectors

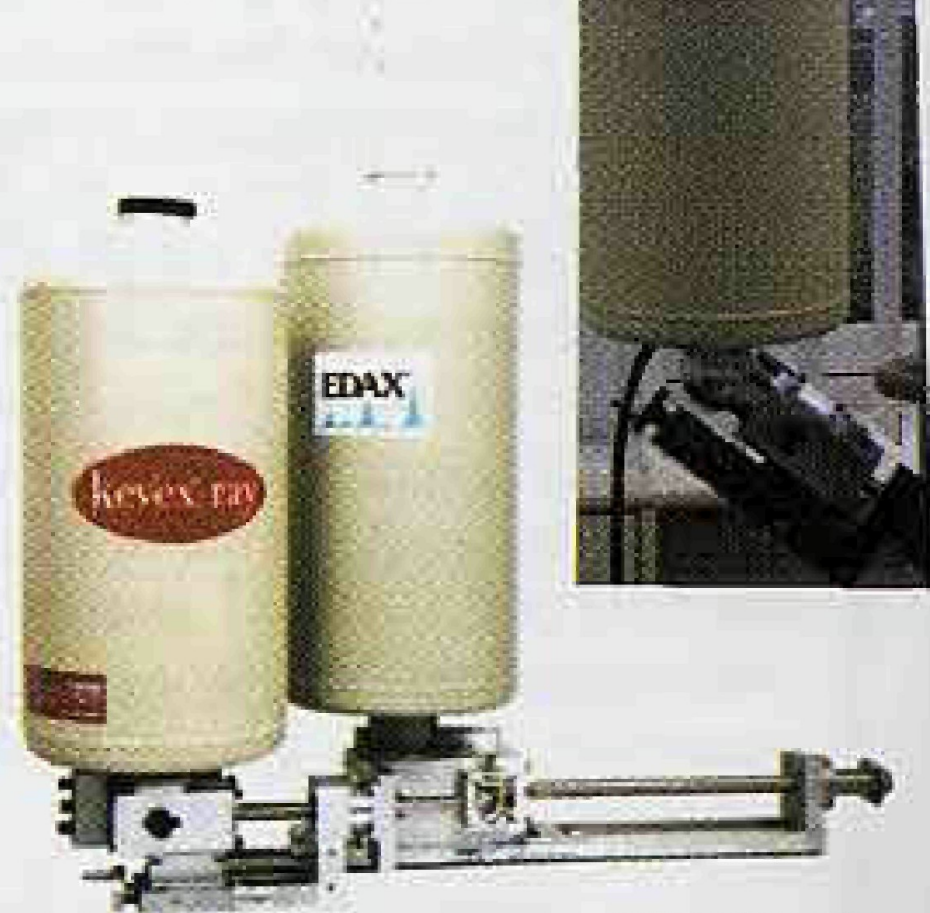

Upgrade your old EDS analyzer with a PC, but keep the detector! 
With any magnification standard the procedures are similar, only at magnifications in excess of $20,000 X$ is the stability of the accelerating voltage likely to require consideration.

Always focus and correct astigmatism at double the photographic magnification switching back to the desired photographic magnification for setting the image intensity and taking the photograph. If possible, orient the specimen structure to sit up-down, left-right, so as to enable measurements of magnification in both $X$ (left-right) and $Y$ (up-down) directions. The specimen should be measured in each direction taking into account as many calibration units as possible.

\section{$\frac{\text { Measurement }}{\text { Number of units } \times \text { Size of one unit }}=$ Magnification}

Results should be within plus or minus $10 \%$ of the readout, with an $X$ to $Y$ comparison of no more than plus or minus $5 \%$. The service engineer should correct errors in excess of this range.

\section{Contamination Rate}

The assessment of contamination rate in a scanning electron microscope is, unlike that of the transmission electron microscope, not a traditional test of performance. The main reason for this lack of procedure is that with the scanning electron microscope the specimen itself is the biggest source of contamination. With the wide variety of specimens used within the scanning electron microscope comparison of rates from instrument to instrument are rarely relevant. However, in auditing a particular laboratory, the authors believe that contamination rate is a valid test of the instrument(s).

The transmission electron microscope test for contamination relies upon the build up of the contamination within a hole in a carbon film decreasing the size of the hole over a known time (Chapman). For the scanning electron microscope the hole is substituted by a gold coated latex particle, in this case the contamination increasing the size of the particle over a known time. Having inserted the specimen wait for the instrument to stabilize. Because of the influence of the specimen on its environment it should be pumped within the microscope for a specific time before commencing the test. One hour is usually required to allow the instrument to stabilize. Find an individual latex particle within the test specimen described earlier and increase the magnification to similar levels as suggested for a resolution test of the instrument. Use the appropriate spot size and working distance that you used for the highest resolution. Take a photograph and note the time. Repeat the photograph having refocused and corrected the astigmatism after exactly twenty minutes.

\section{$\frac{\text { Diam. of Large Sphere }- \text { Diam. of Small Sphere }}{2 \times \text { Time in Minutes } \times \text { Calibrated Magnification }}=$ Contam. Rate}

The increase in the size of the sphere is determined within the calculation, then the rate of contamination, remembering that the contamination has deposited on both sides of the sphere requiring division by 2 to calculate the actual contamination rate on one edge in $\mathrm{nm}$ per minute. Expect a result between $2.5 \mathrm{~nm} / \mathrm{min}$ and $10 \mathrm{~nm} / \mathrm{min}$ depending upon the age of the instrument, state of the vacuum system and the type of specimen routinely used within the instrument.

\section{Drift Rate}

The drift rate test is important at determining the loss of stability, hence performance, as an instrument ages. The isolated sphere is again the subject of this test, the set up procedures being identical to that when taking a contamination rate picture. Once the instrument is stable and the specimen has had time to out-gas the same high resolution conditions are used, with particular care being taken to ensure that the "final" aperture is well aligned. In this case pictures are required at the commencement and at the end of the test but super imposed; a double exposure is required. Set up the instrument and take the first picture. Leave the instrument in exactly the same condition as set up for the photograph taking care not to touch any image movement controls. Repeat the photograph after 20 minutes, the problem here is that excessive focus change will change the magnification and any aperture misalignment will change the position of the sphere. Expose the second picture on the same piece of film and process the film. Remember that most of the drift we see on a scanning electron microscope is due to specimen charge deflecting the beam, this results in apparent specimen movement, not true specimen movement!

\section{$\frac{\text { Distance Moved by the Sphere }}{\text { Magnification } \times \text { Time Minutes }}=$ Drift rate}

In our experience, the drift rate on an instrument in good condition is less than the resolution of the instrument which means even over a 20

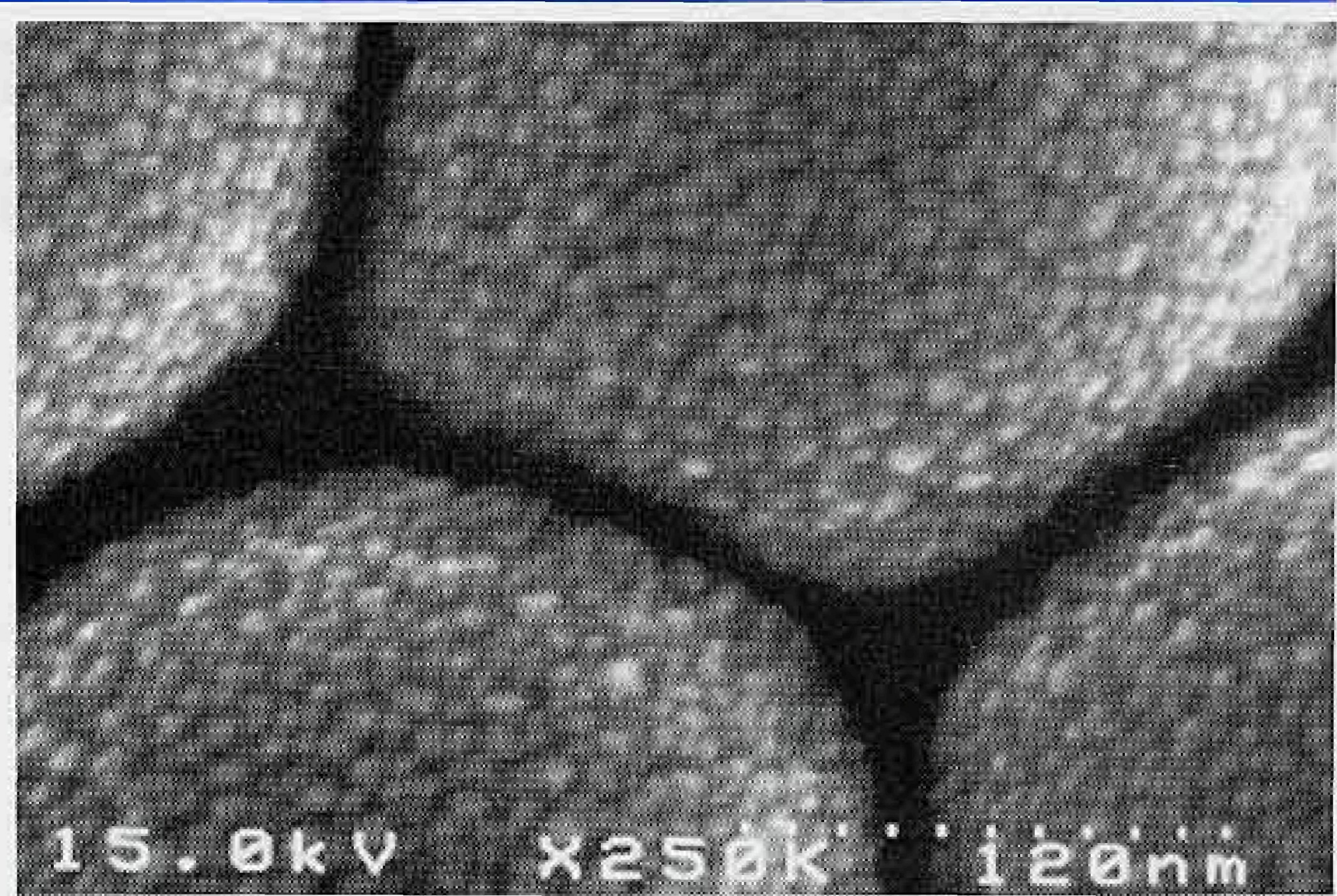

minute period there should not be a discernible shift in the image. If you do detect image movement find another area and perform the test again. Repeated evidence of movement suggests either a poor specimen or stage earth, or problems with the stage movement; all areas that need attention in a well run E.M. unit.

\section{Determining Performance in Transmission Electron Microscopes (Chapman)}

Prior to making any test of the machine, the instrument should be clean and set up in such a condition that the full potential of the instrument may be realized. This requires the filament to be placed in such a position, within the cathode, that at the selected accelerating voltage the emission current will be 30 to 50 micro amps (at $100 \mathrm{kV}$ ) with the bias or emission control approximately in the centre of its range.

\section{Resolution Test}

Place a holey carbon film in the microscope and select the accelerating voltage that is the subject of the test. Switch on the accelerating voltage and leave the instrument in this condition for at least one and a half-hours to allow an oil filled high voltage tank, and the specimen rod, to stabilize. A gas filled high voltage tank will stabilize in a shorter time, probably within one hour. Not until the heat gained by the components within the tank equals the heat lost will the instrument reach maximum stability. Similarly, during this period the specimen rod will be brought to exactly the same temperature as the surrounding components within the instrument

Investigate the specimen at the eucentric position, with a spot size of around half to one micro-metre and a magnification greater than $200,000 \mathrm{X}$.

(C) Protrain 2001

\section{Fresnel Fringes}

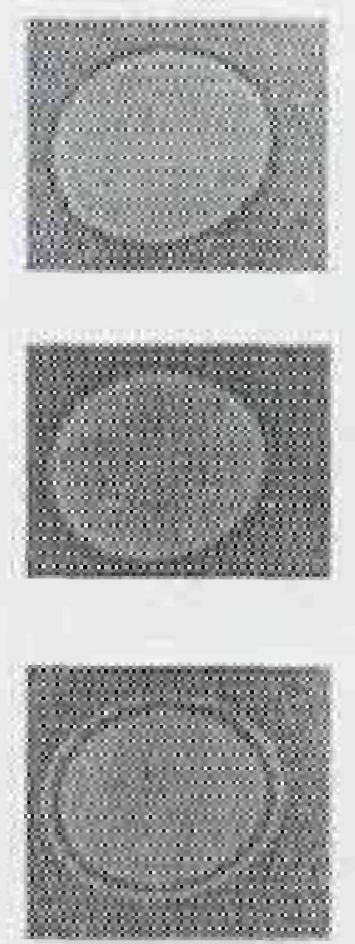

Underfocus white strong

In focus no fringe

Overfocus black strong

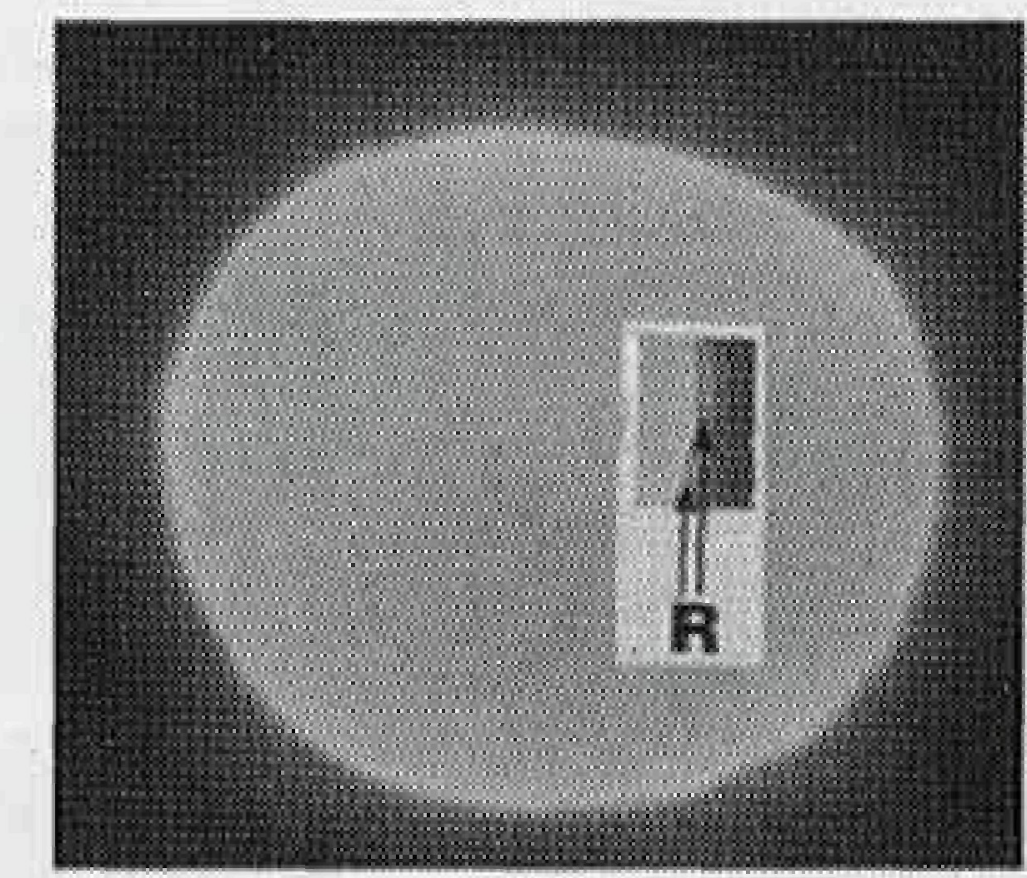

Work with a hole about $2 \mathrm{~cm}$ across at this magnification; remember that you only need to see half a hole, as the other half will mimic what you see in your field of view. Use an overfocus condenser setting for the pictures of a fresh hole having previously set the instrument up on another hole. Do not dwell on the area of interest as this will contaminate the specimen and soften the image, you should expect to use a two to four second exposure. We believe it is not possible to obtain the highest resolution micrograph other than by taking a through focal series. The magnification should be calibrated at the same time by imaging one of the crysatile or carbon lattices. Focus and correct the astigmatism making the fringe finer and finer until you are only just able to detect the fringes all round the hole. Your final focus should make the overfocus fringe only just visible, using this as your first exposure 
in a through focus series turning back towards underfocus. To judge the range required, count the number of steps between a just visible overfocus fringe (black) back to a just visible underfocus fringe (white). Divide this step figure by 5 and use this result as the number of focal steps between each of 6 exposures. The fringes should be measured in each direction. If the astigmatism is not correctly compensated, you should not trust the resolution test. A simple guide to performance is that $0.1 \mathrm{~mm}$ at $200,000 \mathrm{X}$ is equal to $0.5 \mathrm{~nm}$ resolution. Should you desire to determine the highest possible resolution of the instrument, lowering the specimen further in the lens, increasing the lens strength and reducing the aberrations will attain higher performance. This is achieved by adjusting the side entry rod until it requires a higher lens strength to focus (clockwise). Most eucentric systems allow the specimen to be lowered from that level by at least $1 \mathrm{~mm}$.

\section{Measurement (black fringe to white fringe) $=$ Resolution \\ Calibrated Magnification}

\section{Magnification Calibration}

Low magnification calibration standards are available in the form of the transmission electron microscope specimen support grids. The inexpensive grids are usually well documented in accessory catalogues and make very accurate test specimens. There is only one standard that is applicable to the transmission electron microscope at medium to high magnifications it is a carbon replica of a line or cross grating, usually 2160 lines per $\mathrm{mm}$. At magnifications in excess of $80,000 \mathrm{X}$ it is better to use one of the crystal lattice test specimens which will be found in most accessory catalogues. Advice on obtaining the lattice resolution, and the lattices dimensions that may be imaged, are usually found with each specimen purchased.

Accelerating voltage and focal length play a role in the level of magnification being attained. Always set the specimen at the eucentric position to standardize the focal length. With any magnification standard the procedures are similar, only at magnifications in excess of $40,000 \mathrm{X}$ is the stability of the accelerating voltage likely to require consideration. Always focus and correct astigmatism at double the photographic magnification switching back to the desired photographic magnification for setting the image intensity, setting the final focus and taking the photograph. The specimen should be measured in each direction taking into account as many calibration units as possible. With crystal lattice observations, correct the astigmatism on the actual specimen structure and work just underfocus when looking for the lattice. Having found the lattice at higher levels of magnification, you may then drop down to the desired level, refocus, and then take your micrographs.

$\frac{\text { Measurement }}{\text { Number of units } \times \text { Size of one unit }}=$ Magnification
${ }^{\star}$ For a grating, $1 \mathrm{~mm} / 2160=0.4629$ microns

Results should be within plus or minus $5 \%$ of the readout; the service engineer should correct errors in excess of this range.

Contamination Rate

The test for contamination relies upon the build up of the contamination within a hole in a carbon film decreasing the size of the hole over a known time. Having inserted the specimen wait for the instrument to stabilize. Because of the influence of the specimen on its environment it should be pumped within the microscope for a specific time before commencing the test. One and a half-hours, the period required to allow the instrument to stabilize, is ideal. Find a hole within the test specimen that is about 1 to $2 \mathrm{cms}$ across at the desired magnification. You should be working at similar levels to those suggested for a resolution test of the instrument. Use the appropriate spot size and working distance that you used for the highest resolution. Take a photograph and note the time. Repeat the photograph having refocused and corrected the astigmatism after exactly twenty minutes.

$$
\frac{\text { Diam. of Large Hole }- \text { Diam. of Small Hole }}{2 \times \text { Time in Minutes } \times \text { Cal. Magnification }}=\text { Contam. Rate }
$$

The decrease in the size of the hole is determined within the calculation, then the rate of contamination, remembering that the contamination has deposited on both sides of the hole requiring division by 2 to calculate the actual contamination rate on one edge in $\mathrm{nm}$ per minute. Expect a result between $6 \mathrm{~nm} /$ minute and $0.03 \mathrm{~nm} / \mathrm{min}$ depending upon the age of the instrument, if liquid nitrogen traps are in use, the state of the vacuum system and the type of specimen routinely used within the instrument.

\section{- NORTHERN}

LIMITED TIME OFFER

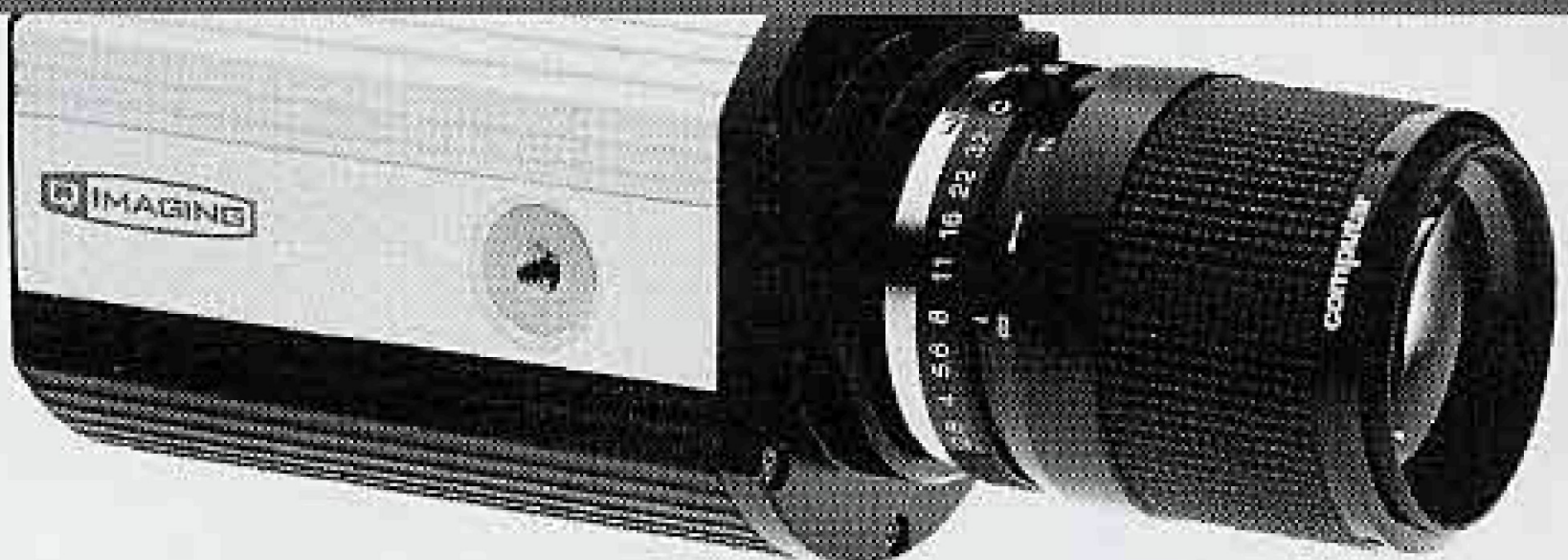

Get the power of Northern Eclipse 6.0 FREE by ordering a QImaging FireWire CCD camera

When you buy a Q Imaging CCD FireWire camera directly from us at the manufacturer's suggested list price, we will include, for a limited time, one FREE Northern Eclipse 6.0 application of your choice. Applications such as Brightness/ Time, Time-Lapse, Image Merging, Fast Capture to Ram, and even De-convolution are available. See the On Sale page of our web site for a full list of applications available with this offer.

\section{www.empix.com}

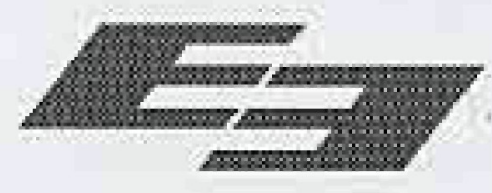

EMPIX

\section{Remove the Vell from SEM \& FIB Samples!}

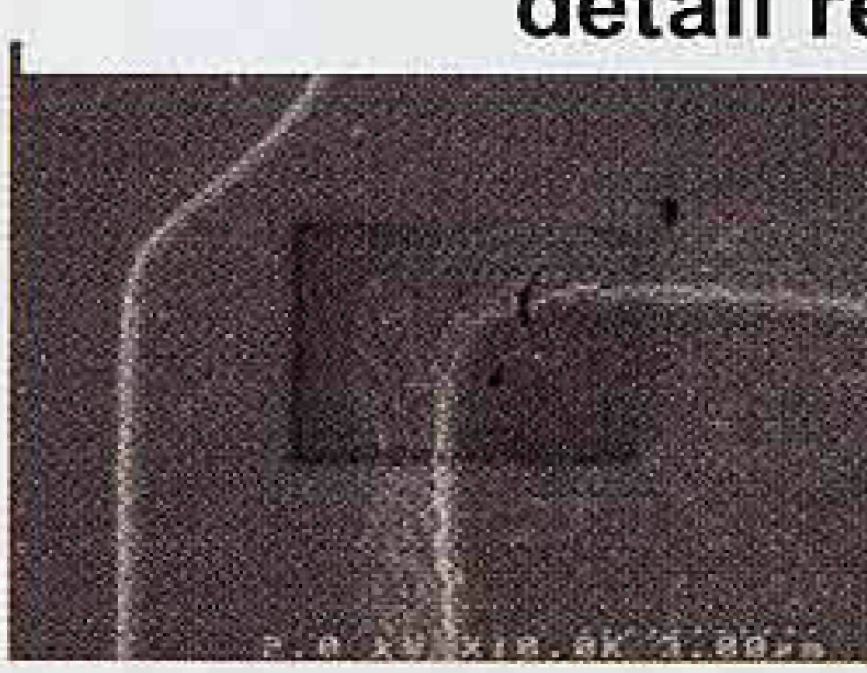

Unwanted Artifact

A short SEM scan started a contamination deposit.

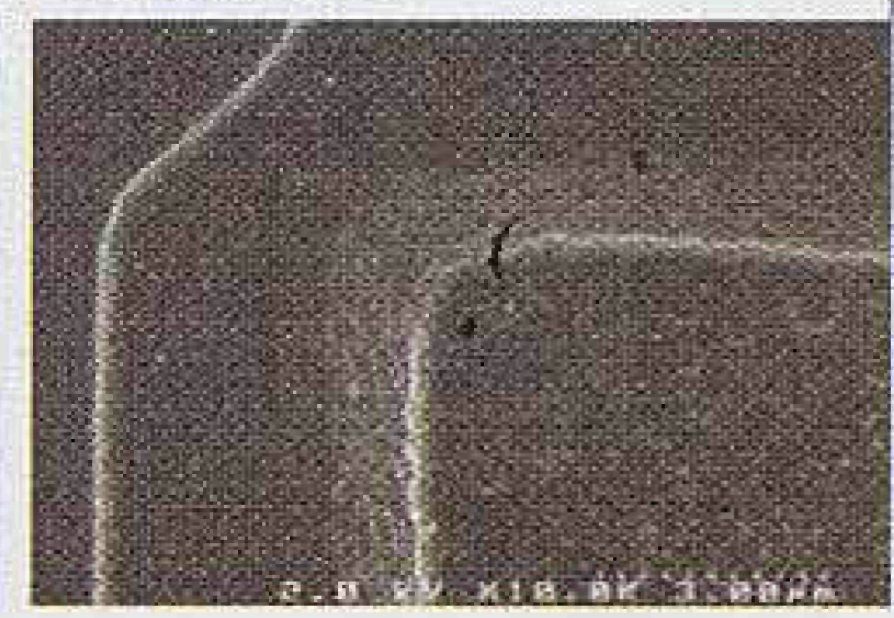

After Evactron Cleaning 2 minutes of cleaning in-situ removed the deposit and prevented new artifacts

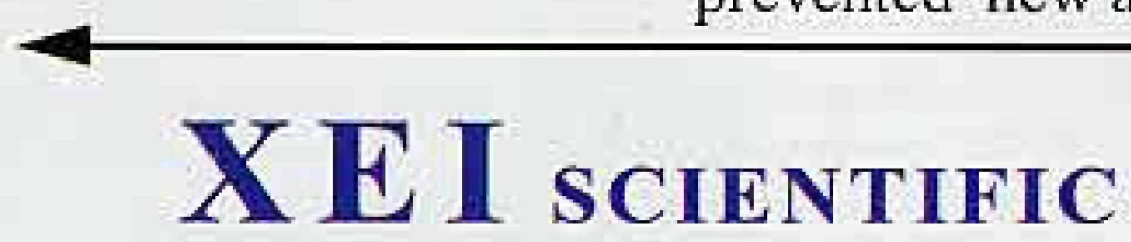

Anti-Contamination Systems

3124 Wessex Way, Redwood City, CA 94061

(650) 369-0133, FAX (650) 363-1659

www.Evactron.com Email: Sales@Evactron.com 
Drift Rate

The drift rate test, which once again uses a hole in a carbon film, is important at determining the loss of stability, hence performance, as an instrument ages. Once the instrument is stable and the specimen has had time to out-gas, the same high resolution conditions are used as with a contamination rate test. In this case, pictures are required at the commencement and at the end of the test but if possible super imposed; a double exposure is required. Set up the instrument as discussed and take the first picture. Leave the instrument in exactly the same condition as you had set up for the photograph, taking care not to touch any image movement controls. Repeat the photograph after 20 minutes. Expose the second picture on the same piece of film and process the film.

\section{$\frac{\text { Distance Moved by the Hole }}{\text { Magnification x Time Minutes }}=$ Drift rate}

\section{Determining Performance in Energy Dispersive X-Rayl Systems \\ Resolution}

Using a fixed kV, spot size, working distance (TEM focal length), tilt, counts per second, live time and processing time, the full width at half max for each peak is measured to determine the spectrometer resolution. For aluminum/manganese or aluminum/cobalt or aluminum/copper specimens check performance in the most commonly used areas of the spectrum. Aluminum with a windowed detector will record around $120 \mathrm{eV}$ with manganese about $10 \mathrm{eV}$ greater than the figure given for the spectrometer, cobalt and copper a little more. The reason for the manganese variation is the EDS manufacturers use a manganese $\mathrm{x}$-ray source to determine the detector resolution, not an electron beam induced signal.

\section{Quantification}

A standard specimen should be obtained which contains known quantities of material of similar levels to the unknown materials analyzed in the laboratory.

In this way, the complete quantification procedure will be checked for accuracy. If rough surfaces or powders are routinely investigated, a standard in these forms should also be considered.

\section{Vacuum State}

The amount of liquid nitrogen required to re-fill the dewar is an indication of the vacuum level within the EDS system. In order to determine the vacuum state a graph of hours per litre should be produced, from which a fall in performance will be more easily recognized and contingency plans put in motion. This fall would indicate a leak, almost certainly pinholes or cracks in the window material; in time the window will fail!

\section{Conclusions}

It is clear from experiences in laboratories around the world specializing in electron microscopy that those who oversee these laboratories rarely check the operating standards. Electron microscopy does not have a "quality" procedure; too many actions are carried out without criticism, which at best results in a very slow level of improvement in technique, if any!

Following the procedures outlined in this paper has been proven to improve the "quality" of results produced by a department. Also, such a well-defined quality structure will place pressure upon internal and external (service) staff and should result in an improvement in the performance level of the instrumentation. If this is not the case, discussion must take place with the senior manager of the service organization to improve the level of instrument service. The past experience of Steve Chapman as an electron microscope service engineer allows the judgment that an engineer will maintain an instrument to a level just above the capabilities of the laboratory in question, improve your standards and that of the instrument will improve also.

It is surprising how much commitment is given when people are being measured; can you imagine a golf course with no holes? When a measurement system is set up the audit team must possess a great deal of integrity and earn respect for fairness and consistency from the auditees.

\section{References}

Chapman S. K. (1986) Checking the performance of the microscope, in: Maintaining and Monitoring The Transmission Electron Microscope (Royal Microscopical Society handbook 08) Available from Protrain $\$ 18$

Chapman S. K. (2001-3) Interactive CD Courses - M6 Monitoring \& Maintaining the EM. Available from Protrain $\$ 100$

Haine M. E. and T. Mulvey (1954) The regular attainment of very high resolving power in the electron microscope. Proc. 3rd Int. Congr. Electron Microscopy, London p. 689.

\section{Microscopy $_{\text {AvD }}$ Microanalysis}

Table of Contents Preview

\section{Volume 9, Number 3, June 2003}

\section{Biological Applications}

- Morphological Characterization of Elastin-Mimetic Block Copolymers Utilizing Cryo- and Cryoetch-HRSEM

Elizabeth R. Wright, Vincent P. Conticello, and Robert P. Apkarian

- Intraspinal Endodermal Cyst: Uitrastructural Study of Abnormal Cilia Khang L. Ho, Dhananjay A. Chitale, and Mohamed E. Salama Imaging Mitochondrial Organization in Living Primate Oocytes and Embryos using Multiphoton Microscopy J.M. Squirrell, R.D. Schramm, A.M. Paprocki, D.L. Wokosin, and B.D. Bavister

\section{Microanalysis}

- Compositional Averaging of Backscatter Intensities in Compounds

John J. Donovan, Nicholas E. Pingitore Jr., and Andrew Westphal

\section{Materials Applications}

- The Correlation between lon Beam/Material Interactions and Practical FIB Specimen Preparation

B.I. Prenitzer, C.A. Urbanik-Shannon, L.A. Giannuzzi, S.R Brown, R.B. Irwin, T.L. Shofner, and F.A. Stevie

- Characterization of Contacting Boundaries between Nanoparticles with LACBED Yiming Yao and Anders R. Thölén

- Electron Radiation Damage of MCM-41 and Related Materials Christopher F. Blanford and C. Barry Carter

News and Commentary

- Calendar of Meetings and Courses

Indexed in Chemical Abstracts, Current Contents, and BIOSIS

MSA members receive both Microscopy Today and Microscopy and Microanalysis FREE!

\section{USEB GOUIPIIEM FOR SALE}

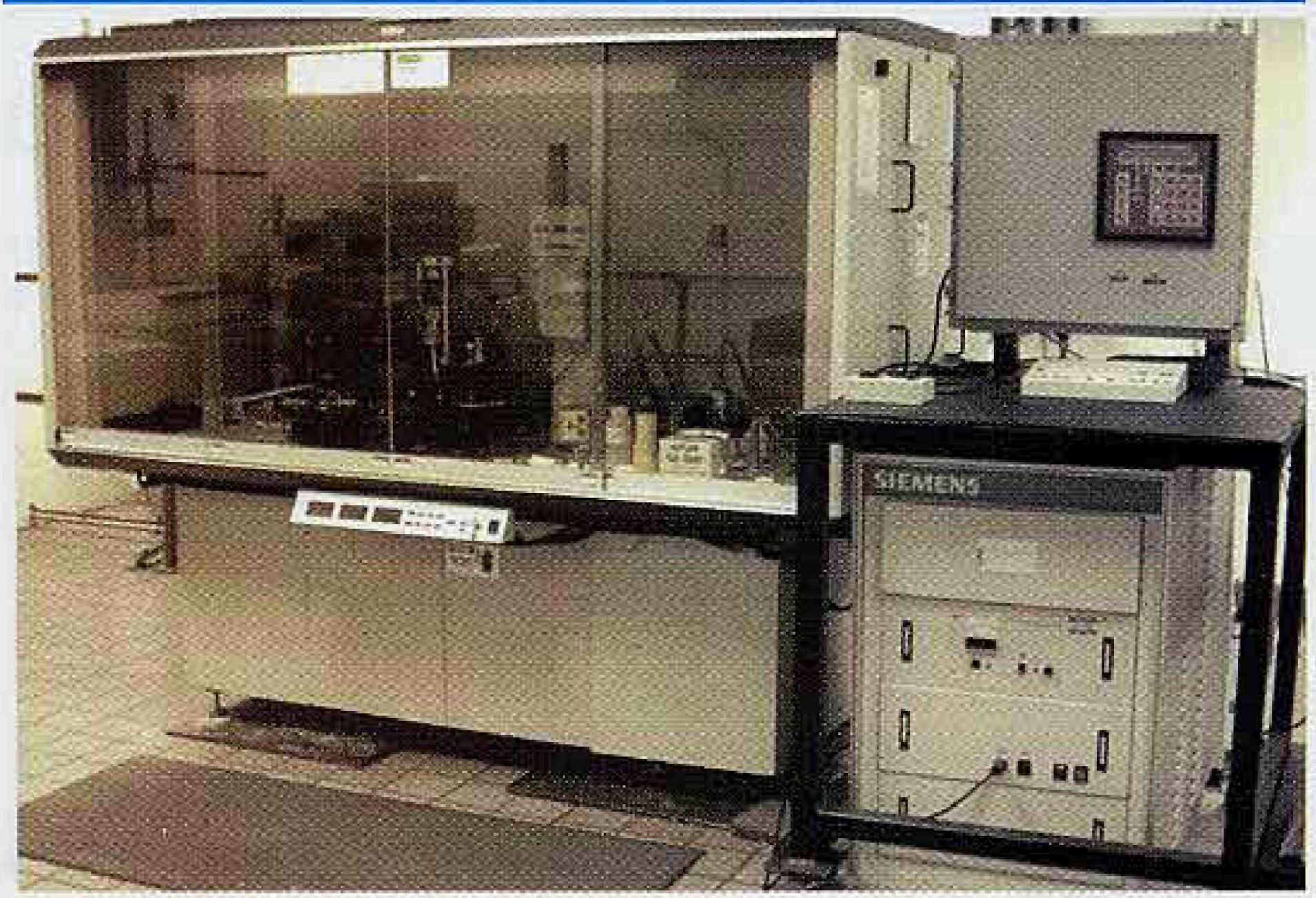

A Siemens MIPX XRD, S/N 91-188. Installed originally on 12/19/91 Excellent working condition. Must Sell! All offers are welcome. If interested, please call Cathy Kelloes, BP, Amoco Fabrics \& Fibers Business Unit, Austell, Georgia 30168. Phone 770-944-4729 or e-mail: kelloecl@bp.com. 


\section{STOP HASSLING WITH}

MULTIPLE SERVICE CONTRACTSL

START by putting all of your instruments under one service contract with MAS (regardless of make or model). Our expert EM SERVICE GROUP has the knowledge and skills to keep your instrument working at its best.

\section{TEM'S / SEM'S \\ PREP EQUIPMENT SPECIAL SERVICES}

HITACHI TOPCON JEOL ISI

\section{AMRAY CAMBRIDGE}

VACUUM COATERS

PLASMA ASHERS SPUTTER COATERS ION MILLS
STAGES

BEAM BLANKERS

CUSTOM DEVICES

\section{NEW NEW NEW}

Authorized service representatives for Gatan preparation equipment and Topcon TEM'S.
Contracts and On-Demand

Emergency Service at

Reasonable Rates from

Factory Trained Specialists.

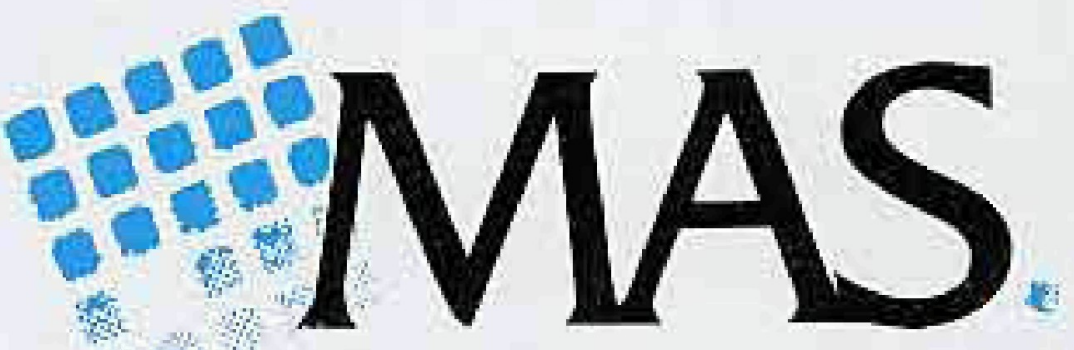

\section{0-421-8451}

3945 Lakefield Court Suwanee, Georgia $30024 \quad 770-866-3200 \quad$ FAX 770-866-3259 616 Hutton Street Suite 101 Raleigh, North Carolina 27606 919-829-7041 FAX 919-829-5518 ADVANCED ANALYTICAL PRODUCTS AND SERVICES

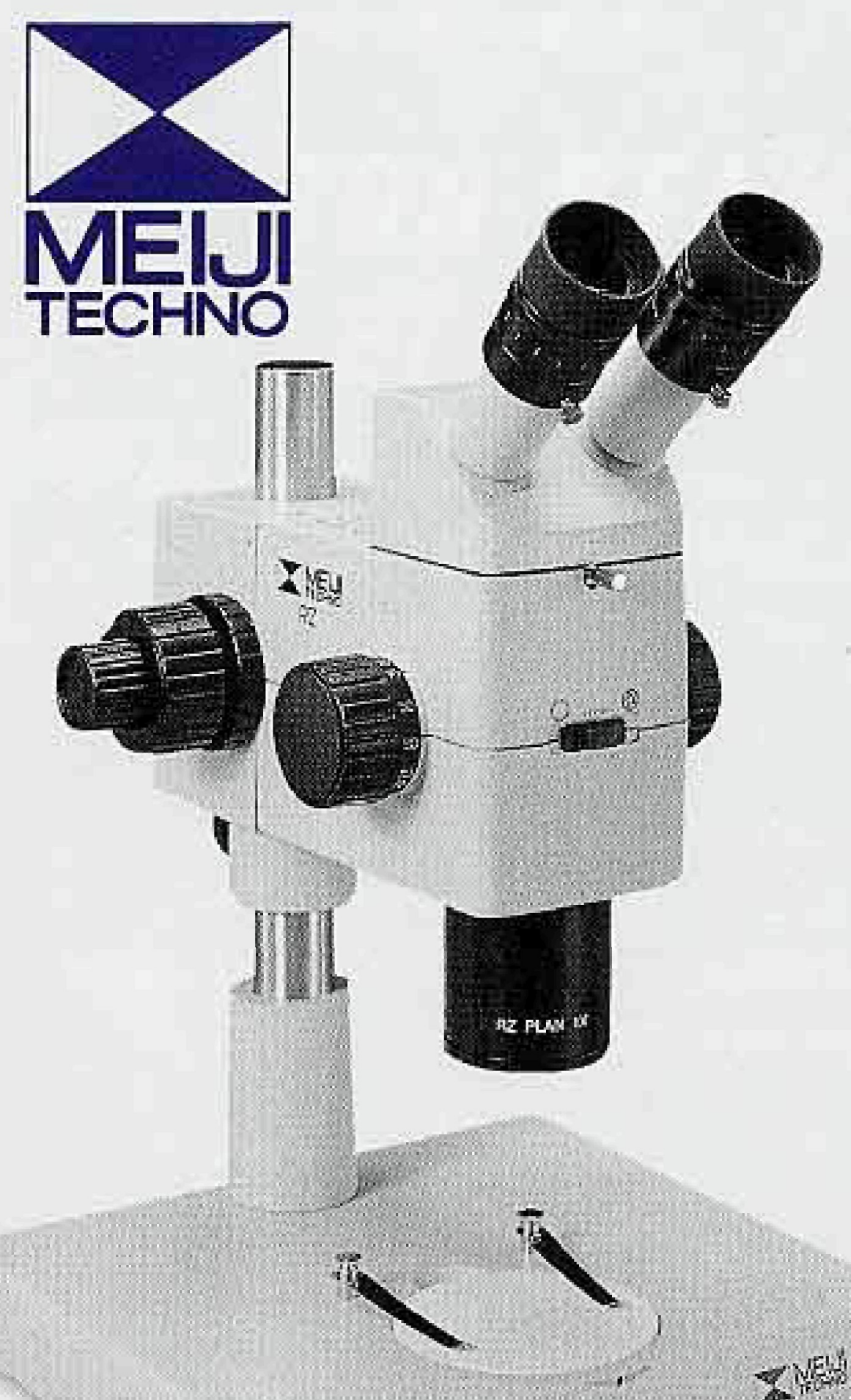

2. ${ }^{2}$

\section{The Meiji RZ Series of Research Stereo Microscopes.}

If you are looking for precision, durability, quality and value in a high performance Stereo Microscope, we invite you to take a closer look at Meiji's RZ Series of Research Stereo Microscopes.

The $R Z$ Series modular system design allows you the freedom to create an ideal instrument for your specific need or application. Featuring a 10:1 zoom ratio, variable double iris diaphragm, and positive detente click stops at 12 positions of magnification. A full range of optional accessories is available, including: Video and photo-micrographic systems, brightfield-darkfield transmitted light stands, ergonomic binocular head, drawing attachment, multiple interchangeable objectives and wide-field eyepieces. Complete system versatility backed by a "Limited Lifetime Warranty."

For more information on these economically priced Stereo Microscopes, please call, FAX, write us or log on to our website today.

\section{MEIJI TECHNO AMERICA}

2186 Bering Drive, San Jose, CA 95131,

Tel: 408.428.9654, FAX: 408.428.0472

Toll Free Telephone: 800.832 .0060 or visit our website at www.meijitechno.com 